\title{
Readiness of teachers for inclusive education of children with disabilities
}

\author{
Natalia Pershina ${ }^{1}$, Marina Shamardina ${ }^{1}$, and Natalia Luzhbina ${ }^{1, *}$ \\ ${ }^{1}$ Altai State University, 656049, 61a Lenina ave., Barnaul, Russia.
}

\begin{abstract}
The research problem is a contradiction between the importance and necessity of implementing the ideas of inclusive education on the territory of the Russian Federation and the creation of favorable conditions for the development and education of children with special educational needs, as well as the insufficient level of readiness of the teachers themselves (one of the main subjects of education) to work in this system. The authors of the article propose a new organizational and personal approach to studying the teachers' readiness for inclusive education of children with disabilities. The authors' structure of the teacher's readiness for the development and implementation of inclusive education in children with disabilities is presented. The practical value of this article is the developed diagnostic methods: "Psychological readiness for inclusive education" and "Assessing the formation of an inclusive culture in educational organizations" and a description of the content components of teachers' readiness for inclusive education.
\end{abstract}

\section{Introduction}

Throughout the world, there is a growing trend in the number of children with various disabilities in development and behavior. Inclusive education, becoming a necessary reality, is actively studied in the foreign literature (Avramidis, E., Bayliss, P., Burden, R., Campbell, J., Gilmore, L., Cuskelly, M., De Boer, A., Pijl, S. J., Minnaert, A., O'Rourke, J., Stoiber, K. C, Gettinger M., Goetz D. et al) [2-7] and domestic literature (E. L. Agafonova, S. V. Alyokhin, I. I. Loshakova, N. M. Nazarova, N. N. Malofeev, I. I. Mamaichuk, N. A. Pershina, E. V Samsonova, M. M. Semago, N. Ya. Semago, S. N. Sorokoumova, A. V. Suvorov, S.A Ulunova, N. N. Khitryuk, S. A. Cherkasova, N. M. Shipitsina, N. D. Shmatko, E. R. Yarskaya-Smirnova, and others). The range of these studies is aimed at the problem of social adaptation and integration of persons with limited health abilities (hereinafter, LHA) and disabled people in contemporary society.

Today, inclusive education is called joint education of children with LIA with normatively developing peers. L. S. Vygotsky was one of the first to point out the need for creating a training system in which a child with special psychophysical development would not be excluded from the society of normative-developing children during the education process [8].

\footnotetext{
* Corresponding author: nluzhbina @ rambler.ru
} 
With this organization of the educational process, all students are involved in the socially active activities of public school life. All this allows to increase the adaptive capabilities of a child and to reveal his/her individual abilities, which corresponds to the modern model of the development of the world community.

However, approbation of the implementation of inclusive education in the Altai Territory and the Altai Republic showed that there were a number of economic and organizational obstacles, among which there was a low willingness of the participants in the educational process to adopt a special child. In Russia, along with common problems, there are some cultural-specific factors that make it difficult to switch to inclusive education, primarily due to the established traditions of teacher training, the peculiarities of the system of general and special education, and the stereotypes existing in our society regarding people with LHA. Alyokhin, Alekseeva, and Agafonova point out that the main psychological "barrier" is the fear of harm to inclusion for other participants in the educational process, negative attitudes and prejudices, professional insecurity of the teacher, and psychological unpreparedness to work with "special" children [1-6].

\section{Materials and methods}

Teachers' readiness to work in conditions of inclusive education is considered by authors through two main indicators: professional readiness and psychological readiness. Professional preparedness is based on information readiness, possession of pedagogical technologies, knowledge of the basics of psychology and correctional pedagogy, knowledge of individual differences in children, readiness of teachers to simulate a lesson and use variability in the learning process, knowledge of individual characteristics of children with various disabilities in development, and readiness for professional interaction and training. Psychological readiness involves the emotional acceptance of children with various types of developmental disorders, readiness to include children with different types of violations in lesson activities, and satisfaction with own pedagogical activity [1-6].

The survey was our method of collecting scientific information, which was carried out to create author's psychodiagnostic tools: (i) a questionnaire "Psychological readiness for inclusive education" (N. A. Pershina), a questionnaire "Assessing the formation of inclusive culture in educational organizations" (T. Booth and M. Einskou in the modification of N. A. Pershina), as well as methods of mathematical and statistical data processing (factor analysis and correlation analysis).

In a study of the psychological determinants of readiness for the acceptance of the students with LHA by the teachers voluntarily participated 210 people living in the Altai Territory and the Altai Republic. Of them were 103 teachers of general education schools, 65 secondary vocational education teachers, and 42 educators of pre-school educational institutions. In a sample were 192 women and 18 men.

In the study of the formation of an inclusive culture, 230 people voluntary took part, namely 100 teachers, 55 parents, and 75 students.

To diagnose teachers' readiness for inclusive education, N. A. Pershina developed the questionnaire "Psychological readiness for inclusive education" and adapted the questionnaire by T. Bout and M. Einskou "Assessing the formation of inclusive culture in educational organizations."

With the aim of constructing a psychodiagnostic tool "Psychological readiness for inclusive education," a pilot study was conducted, where teachers were to freely express their opinions on inclusive education. At this stage, 59 claims were selected for the questionnaire, which were subjected to the evaluation procedure using the 5-point Likert scale. Based on the received material, taking into account that readiness for inclusive education, as for any kind of activity, includes emotional, regulative, and cognitive 
components, 40 valid judgments were selected. The final version of the questionnaire was also offered to the teachers for evaluation.

\section{Results and discussion}

The research results were subjected to the exploratory factor analysis, which allowed to distinguish five factors: "understanding the significance of inclusion"; "caution and skepticism"; "barriers"; "uncertainty and incompetence"; "Meaningfulness." For each of the factors obtained, the reliability $\alpha$-Cronbach coefficients were calculated, which lied in the range from 0.70 to 0.75 , indicating good internal consistency (Table 1 ).

Table 1. Psychological determinants of teachers' readiness for inclusive education ( $\alpha$-Cronbach coefficient).

\begin{tabular}{|l|l|}
\hline Factor (name of the scale) & $\alpha$-Cronbach coefficient \\
\hline F1 "Understanding the importance of inclusion" & 0,75 \\
\hline F2 "Caution and skepticism" & 0,73 \\
\hline F3 "Barriers" & 0,73 \\
\hline F4 "Uncertainty, incompetence" & 0,70 \\
\hline F5 "Meaningfulness" (personal meaning) & 0,70 \\
\hline
\end{tabular}

To verify the consistency of this questionnaire's structure, containing five factors, the original data was verified by the factorial analysis in the program Mplus 7.2. The resulting model showed a satisfactory correspondence to the data; the values of the consistency indices were: $\chi 2=209.82 ; \mathrm{df}=147 ; \mathrm{p}<0.001$; RMSEA $=0.045 ; 90 \%$ confidence interval for RMSEA (0.030-0.059); CFI =0.919; TLI = $0.906(\mathrm{~N}=210)$.

When evaluating the consistency of the model, the following criteria were used: the value of the comparative consensus index (CFI), the Tucker-Lewis consensus (TLI) index of at least 0.90 , and the RMSEA approximation error of less than 0.08 indicate acceptable model fit. This is also confirmed by the values of CFI and TLI being from 0.95 , and RMSEA is less than 0.05 . Thus, the results of the factor analysis and the analysis of psychometric characteristics indicate the validity of the allocation of these scales [7].

Further, in order to identify significant differences in the psychological determinants of teachers' readiness for the inclusion depending on gender, we conducted a comparative analysis using Student's t-test (Table 2).

Table 2. Psychological determinants of teachers' readiness for inclusive education in relation to gender (Student's t-test).

\begin{tabular}{|l|c|c|c|c|c|}
\hline Scale & $\begin{array}{c}\text { Women } \\
(\mathrm{N}=192)\end{array}$ & $\begin{array}{c}\text { Men } \\
(\mathrm{N}=18)\end{array}$ & t-criteria & Df & $\mathrm{p}$-level \\
\hline $\begin{array}{l}\text { Understanding the } \\
\text { importance of inclusion }\end{array}$ & 7,752 & 8,125 & $-0,434$ & 206 & 0,664523 \\
\hline Caution and skepticism & 6,465 & 6,500 & $-0,046$ & 206 & 0,963599 \\
\hline Barriers & 12,406 & 11,875 & 0,561 & 206 & 0,575108 \\
\hline Insecurity, incompetence & 10,382 & 10,125 & 0,253 & 206 & 0,800434 \\
\hline $\begin{array}{l}\text { Meaningfulness } \\
\text { (personal meaning) }\end{array}$ & 5,208 & 5,188 & 0,038 & 206 & 0,969518 \\
\hline
\end{tabular}

As a result of the study, psychological determinants determining the teachers' readiness for inclusive education of children with LHA (understanding of the importance of inclusion, caution and skepticism, barriers, uncertainty and incompetence, meaningfulness) are revealed. The psychodiagnostic tool "Psychological readiness for inclusive education," 
constructed on their basis, was used to interview teachers. Let us turn to the comprehension of the obtained data.

Inclusive education is useful not only for a child with LHA, but also for normatively developing children, because they bring up charity, compassion, and tolerance. So $42 \%$ of the teachers surveyed and $2 \%$ totally disagree with this. $60 \%$ of educators are cautious about inclusive education, because this is a new phenomenon, and it would time to understand and comprehend it. It takes a lot of effort for this kind of work, special techniques and programs are much needed. And only $3 \%$ of teachers are ready to work with children with special needs. $10 \%$ of respondents have different barriers, for instance, that other children and their parents would not accept a child with LHA. And the teacher him/herself would not have accepted such a child in class without having an approval from his/her school administration. Similar fears are absent in $14.5 \%$ of respondents. The destruction of barriers and the unification of public space in obtaining education contribute to changing attitudes in society to disability in general. Therefore, disability is to be considered one of many people's features. $23 \%$ of teachers are not ready to work with children with LHA, because they realize that they do not know how to work with such children and do not understand their psychological characteristics. Another share of teachers $(10.5 \%)$ is confident in competence. Teachers understand that teaching children with LHA is difficult but grateful. And when children with LHA have success in their studies, it inspires and motivates them to work. $48 \%$ of teachers see the meaning of their activities, and $1 \%$ do not.

\section{Conclusion}

Thus, our study clearly demonstrates that the assessing the level of inclusive culture in general education institutions varies depending on the role of the subjects of the educational process: teachers, parents, and trainees.

Diagnosing teachers' readiness to implement inclusive education in the process of psychological and pedagogical support should take into account the complex structure of this phenomenon, which includes a personality component that reflects the individual and psychological characteristics of a teacher, as well as an organizational component that characterizes the teacher's perception of the formation of an inclusive culture in an educational institution.

The obtained results show the need for organizing a systematic educational work to develop a tolerant attitude to children with LHA in society, especially among subjects of the educational process. Programs of psychological and professional support of teachers for the implementation of educational activities in classes with children with special educational needs are also needed. One of the prospects for further research can be the search and analysis of other socio-psychological factors that influence the teachers' readiness to accept and teach children with special educational needs.

\section{References}

1. Ye. V. Agafonova, On the way of adoption: psychological support for parents of children with disabilities (Moscow, 2015)

2. S. V. Alokhina, Psikhologicheskaya nauka i obrazovaniye, 21, 1 (2016)

3. S. V. Alokhina, Sibirskiy pedagogicheskiy zhurnal, 5 (2014)

4. S. V. Alokhina, Sovremennaya zarubezhnaya psikhologiya, 3, 3 (2014)

5. S. V. Alokhina, Psikhologicheskaya nauka i obrazovaniye, 1 (2014) 
6. S. V. Alokhina, M. A. Alekseyeva, Ye. L. Agafonova, Psikhologicheskaya nauka i obrazovaniye, 1 (2011)

7. N. A. Pershina, O. A. Sychev, O. A. Kazantseva, Sbornik trudov XIV Vserossiyskoy nauchno-prakticheskoy konferentsii (Biysk, 2016)

8. N. A. Pershina, M. V. Shamardina, Sbornik nauchnykh trudov po materialam III Mezhdunarodnoy nauchno-prakticheskoy konferentsii (Gorno-Altaysk, 2016) 